\title{
Symbiosis Concept in Bali Communal Dwelling
}

\author{
Garbha, I Putu Adi \\ Postgraduate Student \\ Department of Architecture \\ Institut Teknologi Sepuluh Nopember \\ Surabaya, Indonesia \\ Defiana, Ima \\ Senior Lecturer \\ Department of Architecture \\ Institut Teknologi Sepuluh Nopember \\ Surabaya, Indonesia \\ Prijotomo, Josef \\ Professor \\ Department of Architecture \\ Institut Teknologi Sepuluh Nopember \\ Surabaya, Indonesia
}

\begin{abstract}
Density of urban population due to the flow of urbanization becomes the main global issues. One of the triggers is desire to achieve a more prosperous standard of living. The urbanization continues to double in recent periods. Population growth spreads from center to the periphery of the city.
\end{abstract}

Symbiotic architecture is an approach inspired by the concept biological process. Symbiosis comes from the word 'sym' and 'biosis' which means relationship reciprocity between two adjoining elements. This study used the hybrid method that aims to preserve the architectural elements which have the potential to be reproduced with the latest technology.

The result of the concept of symbiotic architecture is the design crteria for Bali Communal Dwelling that suitable for mixuse space.

\section{Keyword: Symbiosis, Communal dwelling, Hybrid.}

\section{INTRODUCTION}

The density in Kuta has been a problem on the ecological aspect of the city in recent years. For example, the number of hotels in Badung has reached 165 units. One of the effect of that condition is the large numberof waste fored. In addition, according to data from Kuta's Regulation in 2013, the area of green open space is only about $24.48 \%$. Referring to the standard for green open space (RTHK), the minimum green area of a region should be about $30 \%$. Unsufficient green space is due to the indication of the alteration of land in Badung. The development of the Kuta region has brought ecological changes in the region. One of the application of symbios is Co-Living complex Ubud by Alexis Dormier. CoLiving or shared living is a concept that is commercialized by ROAM. The concept is a combination of residence as well as workspace in different locations and atmosphere. Co-livig is one of the norms of modern society. One of its uniqueness is to combine the concept of local architecture (traditional Balinese) in every building. Iti is highlighted by balancing through detail, the order of the masses, as well as the atmosphere of space.

In the era of globalisation and information technology, collaboration becomes an important requirement for all parties to adapt easily in all sectors, whether tourism, business, design, etc. Similarly in the social aspects of society, one of the advantages of areas with high density is the richness and diversity of existing resources. Therefore, it needs a breakthrough in the design of tourism facilities in Kuta, one of them through the Hybrid method in Symbiosis concept that is apllied in this research.

According to the spatial plan and the condition of Kuta, the development of its territory is aimed at becoming a commercial zone. Therefore, in every strategic locations, the designation of cluster buildings are dominated by commercial functions. For example, the area of South Kuta is already filled with commercial buildings, such as middle class hotels, malls, retail, restaurants, etc. The commercial zone is important to support the economic sector of Kuta society.

Problems arise because the percentage of commercial buildings has exceeded the portion. For example, based on the results of field surveys, commercial functions have dominated residential areas (survey location: residential zone in Tuban, South Kuta)

The problems in the Kuta are divided into 3 major contexts. When the scope of the problem is minimized (according to survey location: residential zone in Tuban sub district, South Kuta), the main problem is Kuta is lack of public space. The factors of the problem are identified as:

1. The development of residential areas in urban villages (villages located in the middle of the city) so increased drastically.

2. The number of people is increasing rapidly, both coming from Bali and migrants from outside the region.

3. Houses that are built do not include a lot of public space due to cramped small land.Ease of Use

\section{THEORITICAL REVIEW}

Density is the distance between objects within a certain area. Density in cities is influenced by many factors such as growth in number of buildings and population. This why the city density ratio so relative to each area.

According to Vicky Cheng (2009), the density is divided into 4 kinds based on physical and non-physical influence in an area such as:

1. People Density: The number of people per particular area.

2. Building Density: The number of buildings per area 
3. Spatial Density: Density due to intervention of spatial elements within a particular area

4. Social Density: Density that is more intimate, influenced by relationships and social interaction.

According to Cheng (2009), in addition to physical factors, density conditions are also influenced by social factors. Therefore it takes a good quality environment for people to get together, and interact socially. Since the density is influenced by quite complex factors, there is no absolute measure of the standard of density for each person. The closest parameters are measured on the functional aspect of about $3.5 \mathrm{~m} 2 /$ person for ideal space requirements.

Meanwhile, according to Flachscbart (1979), density conditions are influenced by short building mass configuration (blocks), number of intersection and signage arrangement. According to the results of the study, density conditions can be reviewed to the smallest scale (individual), which is intimate, relative, and complex. According to his understanding, the dwelling is a building that serves as a residence and means of fostering the family. Shelter or home can be used as a parameter to measure the level of welfare of life. Since the earlier time the human way of living continues to grow until now.

According to the Urban Land Institute, public space is a space to accommodate public activities conducted by a number of people, in accordance with the function and theme of each community. Formed because of the need for a place to gather and engage in social interaction. Public spaces are oriented towards social needs. In general, public space is free. There are some functions of public space for a city, including:

a. Open space, is a free space in the form of open area with public activity in it.

b. Central, as a marker of the city center as well as the center of community activities.

c. Liaison (Linear Park), a public space that connects several important buildings or spots within the city.

d. Symbols, as symbols that represent the identity of their city, historically, or in a particular context.

e. Node, as a marker that gives a specific impression to the city

Historically and traditionally, the Balinese people applied a communal pattern of hereditary relations. Prominent features are societal patterns divided based on livelihood. For example farmer communities, artisans, artists, etc.

The traditional architecture of Bali is the concept of Balinese space and building. Inherited and applied for generations by the undagi (Balinese architects). Traditional Balinese architecture philosophy governs spatial and building according to macrocosm and microcosm aspects.
Symbiotic architecture is the concept of an approach that is inspired by biological processes. Symbiosis is derived from the word 'sym' and 'biosis' which means a reciprocal relationship between two adjoining elements. Symbiosis process serves to preserve the different elements but side by side. The concept was implemented in architecture by Kisho Kurokawa in 1960. According to Kisho Kurokawa, the incorporation of 2 different elements in architecture is required to maintain their respective sustainability.

The concept of symbiosis stems from a traditional Japanese architectural philosophy that applies collaboration between modern elements and traditional elements. According to Kisho Kurokawa, in applying the concept of symbiosis one must recognize the sacred zone and the intermediary zone of each element. Sacred zone is owned by a cultural tradition and must be maintained to protect diversity.

\section{METHOD}

Hybrid is one of the architectural design methods that emerged in the post-modern era. It is a combination of several different elements (binary opposition). The hybrid method was initiated by Kisho Kurokawa in 1960, as a development of the concept of symbiotic architecture.

Hybrid method can be divided into 2 strategies, namely through tangible elements (tangible) and intangible (intangible). Tangible elements (teraga) for example building materials, geometry composition, and mass order. While the symbiosis between the elements that are not intangible (intangible) include non-physical aspects, namely space, function, and hierarchy. Therefore, hybrid concept can be executed visually and non-visual.

In his works, the hybrid method was applied to marry traditional Japanese architecture with a stylish international style that was popular at that time.

According to that sense hybrid is the merging of several different elements with domination by one of its element. For example merging between traditional architecture with modern architecture, between new buildings with old buildings.

\section{RESULT}

The location of the design site is located in the residential area of the settlers (J1 Sempati, Banjar Kelan, Tuban Village). According to survey results, about $70 \%$ of the residents in the settlement are immigrants. Previously, the existing land is empty land that is utilized by residents to be open space, for example parking lot, play area, social area, even garbage dump etc.

Along the corridor of the arterial road (primary or secondary) is filled with commercial facilities. Business goals also vary, ranging from middle to elite class. In addition to commercial functions, there are also other functions such as settlements, government, small \& medium industries, to support the tourism sector 

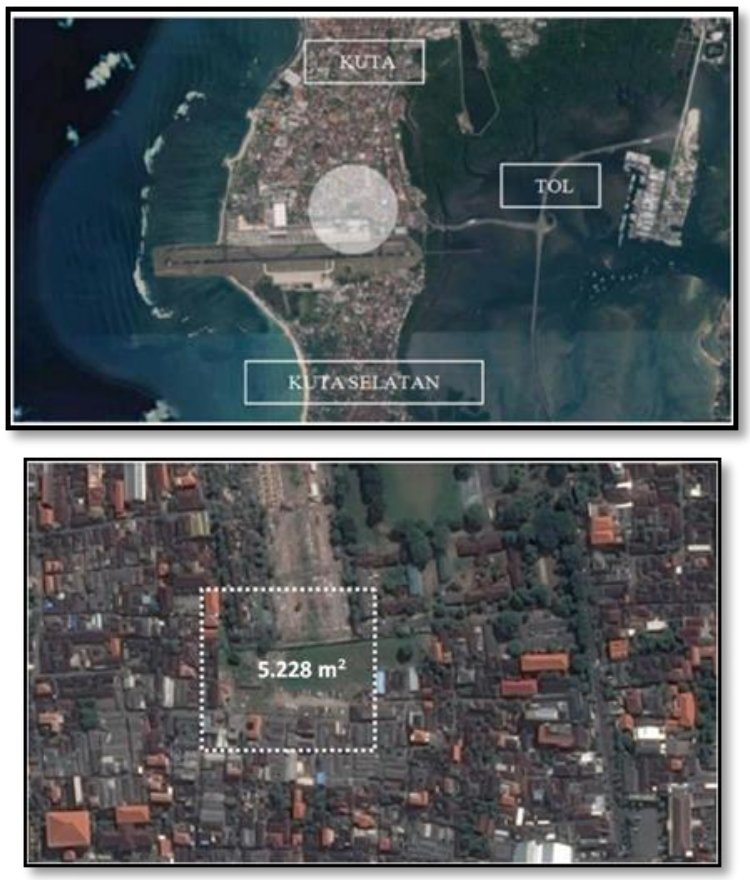

Fig. 1. Site Location

The design site is located within an urban village where most of the people are a group of workers. During the day during office hours, the area is used as a parking area. While in the afternoon, children often play in the area. The physical condition of the land is neglected and has not been utilized optimally
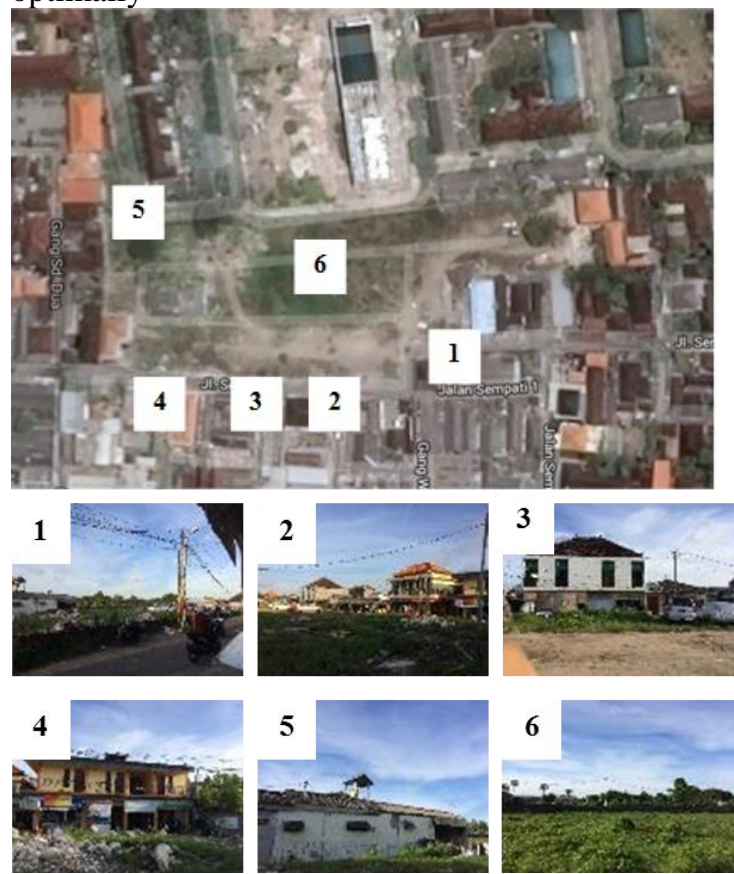

Fig. 2. Existing Site Part 1

The location of the site is surrounded by a residential area, which averages about 1-2 stories high. The site is passed by a road corridor with $2-4 \mathrm{~m}$ width. The speed of the circulation of the vehicle is relatively slow because there are many children playing. The unkempt condition of the land gives bad impression, especially because of the existing waste.

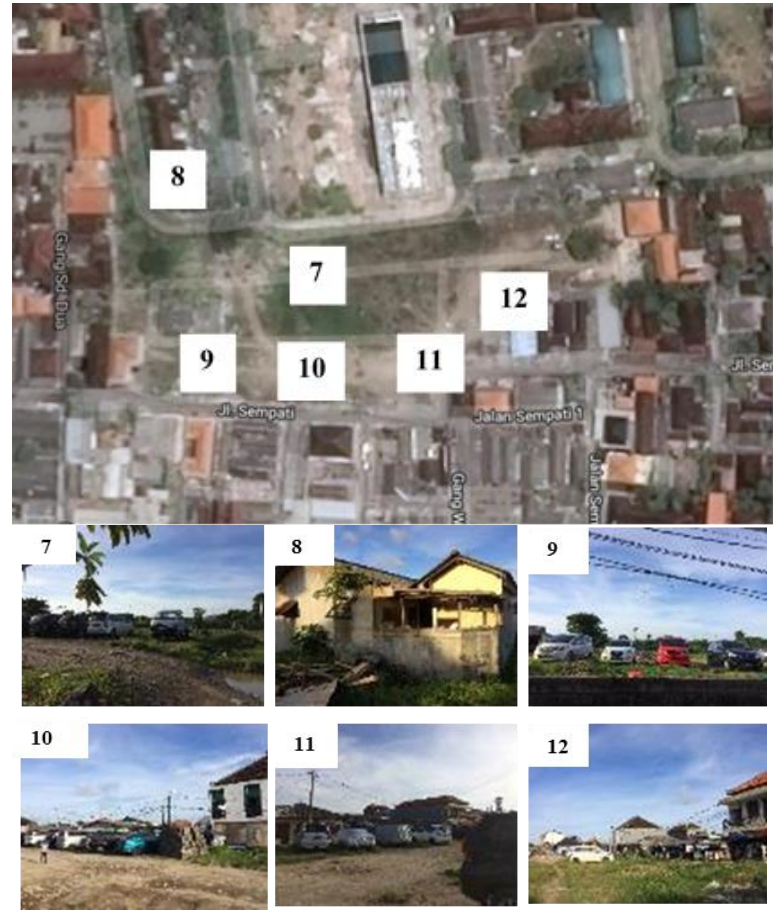

Fig. 3. Existing Site Part 2

Around the design site there are many commercial facilities. The existing commercial facilities are for the middle class, making them affordable for workers. Less function is the public space at the same time accommodate the commercial function

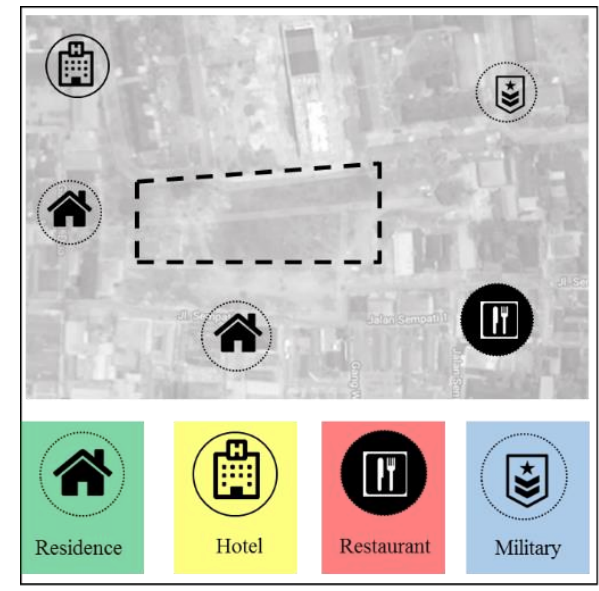

Fig. 4. Facilities

According to the Kuta spatial plan, the green open space in Kuta is below standard, about $+24 \%$. Generally, the number of green space in urban areas is at least $+30 \%$. Therefore, the area of green open space area in Kuta need to be increased in order to meet the required standards.

In some urban areas there are two ways to increase the amount of green open space and public space, namely:

1. Mixuse public space, the addition of public space in buildings that are used for various activities

2. Vertical garden, addition of landscape elements on various features of buildings and public spaces. For example greenroof, glass farm, green streetscape, etc. 


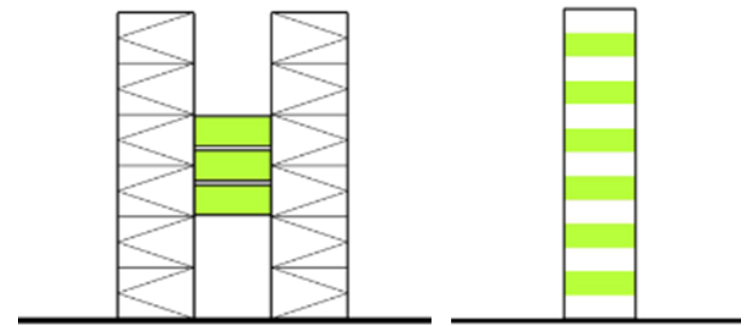

Fig. 5. Vertical Garden

With vertical green \& public space strategy, the area of green space can be added in order to improve the environmental quality in urban areas. Dense area interventions with landscape elements are often exemplified by metropolitan cities.

Concerning the issue of urban area density, it can be helped by a symbiotic theory approach initiated by Kisho Kurokawa (1960s). Although there has been a long time since the theory was first applied, the concept of symbiotic architecture and its applications continue to be developed because it is still relevant to the problem now.

The symbiotic architecture described by Kisho Kurokawa can be applied trough hybrid method, through 3 different stages, including:

1. Eclectic, ie, using the typology of forms and architectural elements of the past, which have the potential to be reappointed.

2. Modificationi, change the elements that are presented again by shifting, pulling, rotating and reversing the geometry

3. Combination, incorporating elements that have been modified in the new design according to hierarchy and needs.

The hybrid method aims to preserve architectural elements that have the potential to be reproduced with the latest technology. Therefore, the concept of symbiotic architecture can be applied to problems in Kuta to maintain the quality of the environment and the diversity of its people.

Kisho Kurokawa's symbiotic concept is divided into 3 parts, including: (1) symbiosis between interior \& exterior, (2) transitional space symbiosis, (3) multicultural symbiosis. One of them, the concept of intermediate space, is present because of the 'sacred space'. Therefore it takes a transitional space to bring together different elements

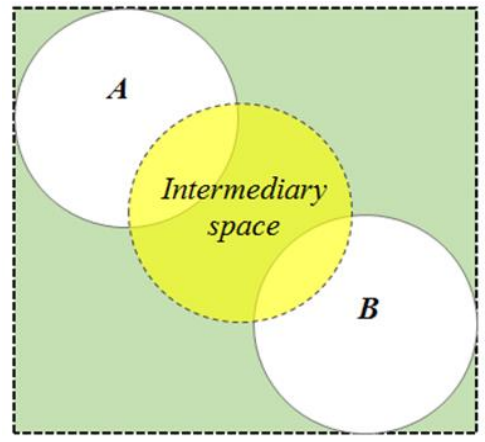

Fig. 6. Symbiosis Concept
In Balinese architecture, the concept of Sanga Mandala divides zoning in a traditional Balinese house into 3 parts called Tri Mandala, which consists of:

1. Main mandala is the zone that has the highest level, consisting of a holy place, and bedroom.

2. Madala mandala, which is a zone that has a moderate level, consisting of houses, bedrooms, and space gathered.

3. Nista mandala, which has the lowest level, consisting of service space, such as kitchens and bathrooms.

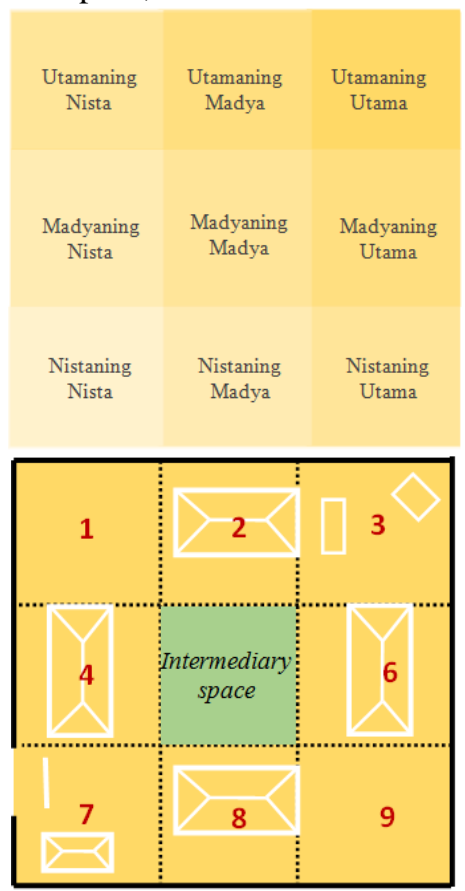

Fig. 7. Ballinesse Architecture Concept

\section{A. Zoning Analysis}

According to the concept of traditional Balinese architecture, residential zoning has a symmetrical pattern with natah (park) in the middle as the center point (vocal point). While in the design of communal dwelling, the concept of natah applied in the same way, placed in the middle as a communal space $\&$ vocal point.

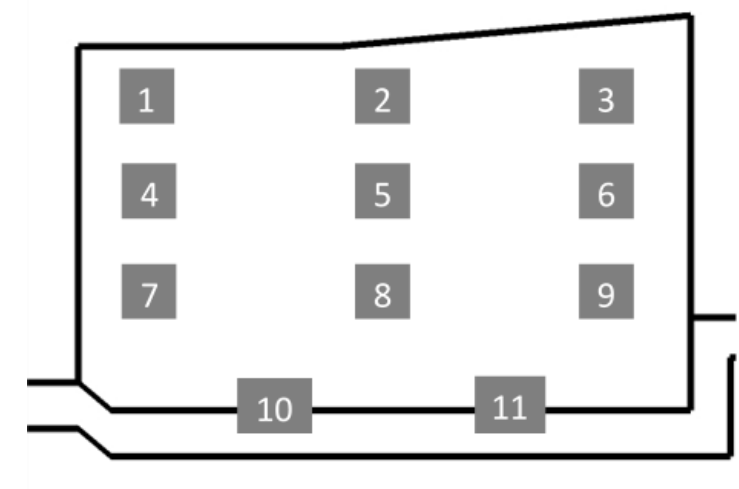

Fig. 8. Bllinesse Zoning 
In the design of communal dwelling, also required the existence of intermediate space or mediator as a meeting place of users who come is from various regions. Therefore, the concept of natah in traditional Balinese house is presented with different execution.

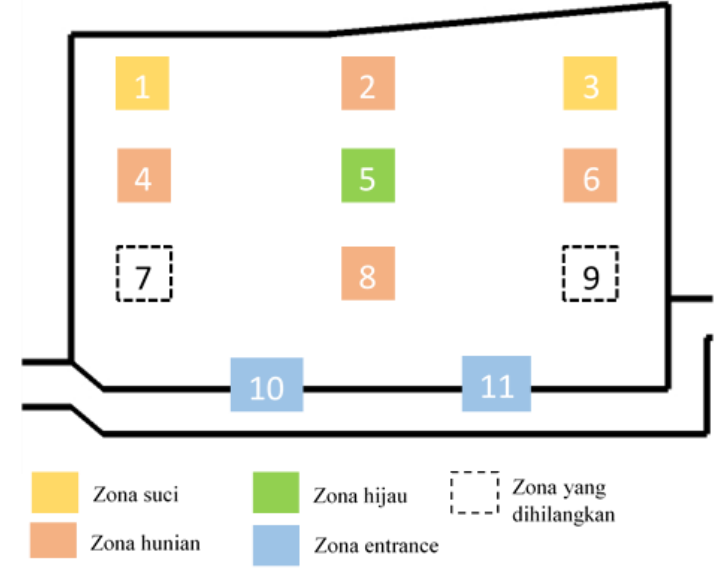

Fig. 9. Analysis of Ballinesse zoning with symbiosis concept

1 and 3 are holy zones that can be combined into 1 zone. Zones 2, 4, 6, and 8 are occupancy zones that can be reduced to 2 zones. Zone 5 is a green zone that is maintained as an intermediary zone. Zones 7 and 9 are service zones removed as well as incorporated into residential zones. While zone 10 and 11 are zone of entrance which can be merged into 1 zone.

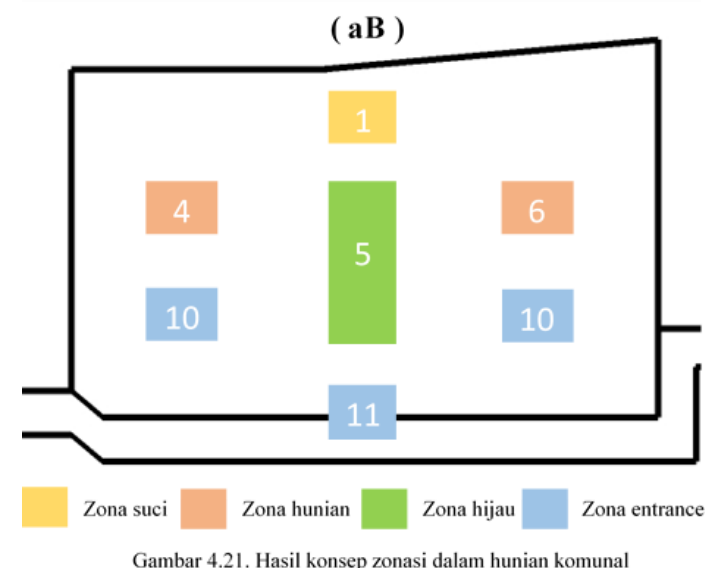

The hybrid method was applied to zone 4,5,6 as the main requirement of Bali communal residential design. Zone 5 is an intermediary space between zones 4 and 6 . That zone as is an application of the concept of natah in a traditional Balinese house. The development of the idea of the concept of symbiosis will be passed on zones 4 and 6 as a major need in the design process. Zone 10 is a transition zone for maintaining privacy within communal dwellings. Its development is functioned as a building supporting facilities for communal dwelling.

The design application is a bridge or sky bridge that connects building masses 1 and 2 at the top elevation (3-4 floors). The goal is to (1) reduce the built area of the land and (2) increase the green open space between the buildings (floating).

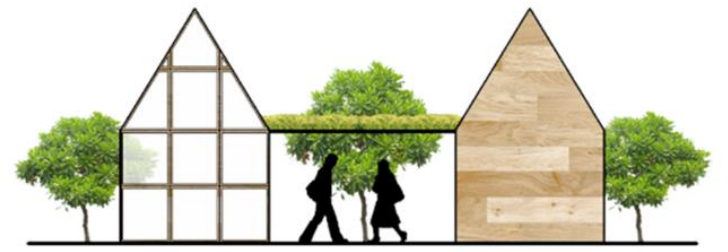

Fig. 10. Intermediate Space
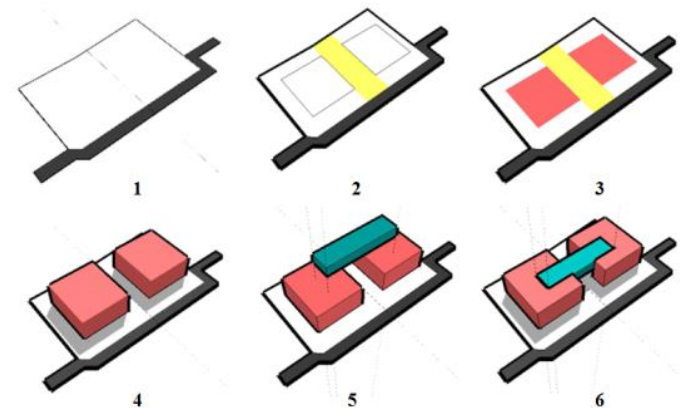

Fig. 11. Design Process

Design criteria are obtained from the literature review, theoretical basis, and field observation results. Here are some design criteria of Bali Communal Shelter with a symbiotic architectural approach, such as:

1. Communal dwelling located in the middle of a crowded Kuta area and has a population of various regions (multiethnic \& multicultural)

2. Have communal space between room and floor units.

3. Has a communal space that connects between the masses building.

4. Have a communal space that is easily accessible by users and surrounding communities

5. Represents Balinese architectural features in a modern form

\section{CONCLUSION}

The density in Kuta has been a problem on the ecological aspect of the city in recent years. Hybrid is one of the architectural design methods that emerged in the postmodern era. It is a combination of several different elements (binary Design criteria are obtained from the literature review, theoretical basis, and field observation results. There are some design criteria of Bali Communal Shelter with a symbiotic architectural approach, such as Communal dwelling located in the middle of a crowded Kuta area and has a population of various regions (multiethnic \& multicultural), have communal space between room and floor units. has a communal space that connects between the masses building, have a communal space that is easily accessible by users and surrounding communities, represents Balinese architectural features in a modern form

\section{REFERENCES}

[1] Flachsbart, P. G. (1979) 'Residential site planning and perceived densities', Journal of the Urban Planning and Development Division, vol 105, no 2, pp103-117

[2] Chan, Y. K. (1999) 'Density, crowding and factors intervening in their relationship: Evidence from a hyperdense metropolis', Social Indicators Research, vol 48, pp103-124

[3] Breheny, M. (2001) 'Densities and sustainable cities: The UK experience', in M. Echenique and A. Saint (eds) Cities for the New Millennium, Spon Press, London, New York 
[4] Kurokawa, Kisho. (1991). Intercultural Architecture: The hilosophy of Symbiosis. Aia Pr; 1 Eddition.

[5] Cheng, Vicky. (2010). Understanding density and high density. Designing high-density cities for social and environmental sustainability. 3-17.

[6] Greater London Authority (2003) Housing for a Compact City, GLA London

[7] Zacharias, J. and Stamps, A. (2004) 'Perceived building density as a function of layout', Perceptual and Motor Skills, vol 98, pp777-784 